\title{
GKK1032A , a secondary metabolite from Penicillium sp. IBWF-029-96, inhibits conidial germination in the rice blast fungus Magnaporthe oryzae
}

\author{
Jens Becker ${ }^{1}$, Johannes C Liermann ${ }^{2}$, Till Opatz ${ }^{2}$, Heidrun Anke ${ }^{1}$ and Eckhard Thines ${ }^{1}$ \\ The Journal of Antibiotics (2012) 65, 99-102; doi:10.1038/ja.2011.114; published online 14 December 2011
}

Keywords: fungicide; GKK1032A 2 ; inhibition of conidial germination; Magnaporthe oryzae; pyrrocidine B

The rice blast fungus Magnaporthe oryzae is the most important pathogen on cultivated rice because of its economic relevance and destructiveness. ${ }^{1}$ Blast disease caused by this heterothallic ascomycete destroys about $10-30 \%$ rice yield every year. ${ }^{2}$ In order to infect and colonize the host plant Oryza sativa, conidia of the fungus attach to the leaf surface and germinate by sending out a germ tube. Induced by the hard hydrophobic surface, appressoria required for penetration differentiate. Within the specialized infection structure compatible solutes, for example, glycerol, accumulate. ${ }^{3}$ The solutes are retained within the cell by a melanin layer. As a consequence, water flows into the infection structure to generate turgor required for a mechanically penetration of the plant cuticle. As the functionality of the appressorium is an essential prerequisite for a successful infection of the host plant, the melanin layer is a pathogenicity factor in M. oryzae. Agrochemicals interfering with the biosynthesis of the biopolymer, for example, tricyclazole, have been successfully used in the past as protective agents. ${ }^{4}$ After penetration, the hyphae disperse within the plant to form conidiophores and conidia. The spores are spread in the field via wind and water. ${ }^{2}$

Due to the resistance development against commercially available fungicides, there is a demand for lead structures for the development of novel fungicides. ${ }^{4}$ Secondary metabolites from nature have in the past been used as lead structures for successful pesticides. The widely used class of QoI (quinone outside inhibitor)-fungicides is based on the structure of strobilurin A, a secondary metabolite found in cultures of the basidiomycete Strobilurus tenacellus. ${ }^{5}$ As fungi represent an almost inexhaustible reservoir for natural compounds, screening approaches are conducted for the identification of new secondary metabolites interfering either with pathogenic differentiation or fungal vegetative growth. In this course, compound GKK1032A $\mathrm{A}_{2}$ (1) was identified from cultures of the fungus Penicillium sp. IBWF-029-96. The compound has been described as a metabolite from fungal cultures. In this note, we describe a biological activity of this compound, which has not been reported before. ${ }^{6,7}$

\section{EXPERIMENTAL PROCEDURE}

Organisms

Penicillium sp. IBWF-029-96 and the unidentified strain IBWF-012-06 are stored in the culture collection of the Institute of Biotechnology and Drug Research (IBWF e.V.), and was cultured at room temperature on yeast malt glucose medium consisting of $4 \mathrm{~g}$ yeast extract (Becton Dickinson $\mathrm{GmbH}$, Heidelberg, Germany), $10 \mathrm{~g}$ malt extract (Fränkle \& Eck, Fellbach, Germany), $10 \mathrm{~g}$ glucose and $18 \mathrm{~g}$ agar per 11 tap $\mathrm{H}_{2} \mathrm{O}$. The $\mathrm{pH}$ was adjusted with $1 \mathrm{~N} \mathrm{HCl}$ to 5.5 prior to sterilization.

M. oryzae strain 70-15 was obtained from the Fungal Genetics Stock Centre, Kansas City, KS, USA. The strain was cultured on complete medium (CM) medium as described previously. ${ }^{8}$ Botrytis cinerea, Fusarium graminearum and Phytophthora infestans were provided by BASF SE.

\section{Fermentation and isolation}

The strain Penicillium sp. IBWF-029-96 was fermented in yeast malt glucose medium in a 20-1 fermenter (Biostat A-20, Braun Melsungen, Melsungen, Germany) at room temperature with aeration $\left(4.51 \mathrm{~min}^{-1}\right)$ and agitation (120 r.p.m.). A well-grown culture $(200 \mathrm{ml})$ in the same medium was used as inoculum. Daily samples were withdrawn to measure $\mathrm{pH}$, glucose and maltose content as well as mycelial dry weight and in order to quantify the bioactive secondary metabolite as described below. The fermentation was stopped after 8 days, when glucose in the culture broth was depleted. The mycelium containing the bioactive compound was separated from the culture fluid by filtration and lyophilized. The compound was extracted from lyophilized mycelium (101.84 g) with 31 of methanol/acetone (1:1). The culture fluid did not contain bioactive compounds, and was therefore discarded. The organic extract was dried with $\mathrm{Na}_{2} \mathrm{SO}_{4}$ and concentrated to yield $6.45 \mathrm{~g}$ of an intermediate product. Chromatography on silica gel in cyclohexane-ethyl acetate (silica gel 60, $63-200 \mu \mathrm{m}, 90 \mathrm{~g}$, column size $24 \times 4.5 \mathrm{~cm}$, Merck, Darmstadt, Germany) and elution with increasing concentration of ethyl acetate yielded $272 \mathrm{mg}$ of a second intermediate product. The fraction containing the bioactive metabolite was eluted with $70 \%$ ethyl acetate. A third intermediate product $(117 \mathrm{mg})$ was obtained by using a Chromabond $(\mathrm{C} 18 \mathrm{ec})$ column and elution with water$\mathrm{MeCN}$ (15:85). Final purification ( $46.8 \mathrm{mg}$ ) was achieved by HPLC using a Nucleosil 100-5 C18 column $(21 \times 250 \mathrm{~mm}, 5 \mu \mathrm{m}$, Merck). The bioactive

${ }^{1}$ Institute of Biotechnology and Drug Research, Kaiserslautern, Germany and 2Johannes Gutenberg University Mainz, Institute of Organic Chemistry, Mainz, Germany Correspondence: Dr E Thines, Institute of Biotechnology and Drug Research (IBWF), Erwin-Schroedinger-Strasse 56, Kaiserslautern D-67663, Germany. E-mail: thines@ibwf.de

Received 30 August 2011; revised 26 October 2011; accepted 9 November 2011; published online 14 December 2011 
compound was isolated by using an isocratic method with $78 \% \mathrm{MeCN}$ in $\mathrm{H}_{2} \mathrm{O}$ at a flow rate of $28 \mathrm{ml} \mathrm{min}^{-1}$. HPLC was performed in a preparative Jasco modular HPLC system (Jasco, Gross-Umstadt, Germany) consisting of two binary pumps (PU-1586) and the multi-wavelength detector UV-1570 M. The fermentation samples were analyzed on an Agilent 1100 Series HPLC (Agilent Technologies, Waldbronn, Germany) equipped with a LiChrospher 100 C18 column $(125 \times 4 \mathrm{~mm}, 5 \mu \mathrm{m}$, Merck).

The appearance of the active compound GKK1032A $(\mathbf{1})$ in the daily samples was monitored with the help of a calibration curve created by analytical HPLC using different concentrations of purified compound.

Structural analysis was carried out on a Bruker Avance-II 400 NMR spectrometer equipped with a $5-\mathrm{mm}$ BBO probehead and on a Perkin-Elmer 241 polarimeter.

\section{Biological assays}

Antimicrobial activity of the compounds was assessed by using simple agar-diffusion assays with fungi and bacteria as test organisms. The test was carried out as described previously. ${ }^{9}$ The maximum concentration used was $100 \mu \mathrm{g}$ per filter disc. The following organisms were tested: Bacteria: Bacillus brevis, B. subtilis, Micrococcus luteus, Enterobacter dissolvens, Staphylococcus aureus; Fungi: Candida albicans, M. oryzae, Mucor miehei, Nematospora coryli and Paecilomyces variotii.

Nematicidal activity against Caenorhabditis elegans and Meloidogyne incognita was assessed as described previously. ${ }^{10} \mathrm{~A}$ maximum concentration of $50 \mu \mathrm{g}$ of the compound per well was used.

Cytotoxic activity against Jurkat (DSMZ ACC 282) and Colo-320 (DSMZ ACC 144) cells was assayed as described previously. ${ }^{11,12}$ Both cell lines were grown in RPMI 1640 medium (Invitrogen, Karlsruhe, Germany).

The inhibition of conidial germination was assayed according to Rieger et al..$^{13}$ and carried out in triplicates. Spores of M. oryzae were harvested with the help of a glass spatula and distilled $\mathrm{H}_{2} \mathrm{O}$. The harvested material was filtered and the supernatant was centrifugated $\left(1000 \mathrm{~g} \mathrm{~min}^{-1}\right)$. The pellet was dissolved in distilled $\mathrm{H}_{2} \mathrm{O}$. The activity was tested in 96-well plates (Greiner Bio-One, Kremsmünster, Austria) with an end concentration of $1 \times 10^{5}$ spores per $\mathrm{ml}$ and a total volume of $200 \mu \mathrm{l}$. After $24 \mathrm{~h}$ of incubation at room temperature, germinated and not germinated spores were counted.

Phytotoxic effects were tested as described before. ${ }^{13}$ Seeds of Setaria italica, Lepidium sativum, O. sativa CO-39 and Triticum aestivum RIBAND were used. The assay was performed thrice. Seeds were grown in sterile 24-well plates on filter papers with 10 and $25 \mu \mathrm{g}$ of purified compound in $250 \mu \mathrm{H}_{2} \mathrm{O}$. Additionally, leaves of $O$. sativa were treated with the compound.

In order to assess the protective effect of $\mathrm{GKK} 1032 \mathrm{~A}_{2}$ (1) on rice plants, harvested spores of $M$. oryzae were dissolved in $0.2 \%$ gelatine to a concentration of $1 \times 10^{5}$ spores per $\mathrm{ml}$. This suspension was mixed with the compound to get concentrations up to $10 \mu \mathrm{g} \mathrm{ml}^{-1}$. Five-hundred $\mu \mathrm{l}$ of the respective suspensions were sprayed on leaf segments of 21-day-old rice plants placed on a water-agar plate. The leaf segments were incubated at $27^{\circ} \mathrm{C}$. After 5 days, appearing lesions were counted in an area of $1 \mathrm{~cm}^{2}$. The test was carried out in triplicates.

The mitochondrial respiration of $M$. oryzae in presence of $\mathbf{1}$ was monitored as described previously. ${ }^{13}$

The fungal strain IBWF-029-96 was identified as Penicillium sp. Its conidiophores showed all morphological characteristics of the genus as described. ${ }^{14}$ Previous fermentation experiments showed that $\mathbf{1}$ was produced upon cultivation in malt extract medium. It was furthermore shown that higher aeration shortened the time needed for the culture to reach the stationary phase. However, under these conditions the concentration of bioactive compound was found to significantly lower (data not shown). Figure 1 shows a fermentation diagram for the submerged cultivation inclusive the recorded fermentations parameters. After 8 days of cultivation, the fermentation was stopped. The production of 1 started at day 5 and the concentration increased constantly until the end of fermentation. Bioactivity-guided purification led to the isolation of $46.8 \mathrm{mg} \mathrm{GKK1032 \textrm {A } _ { 2 }}$ (1). The structure of $\mathbf{1}$,

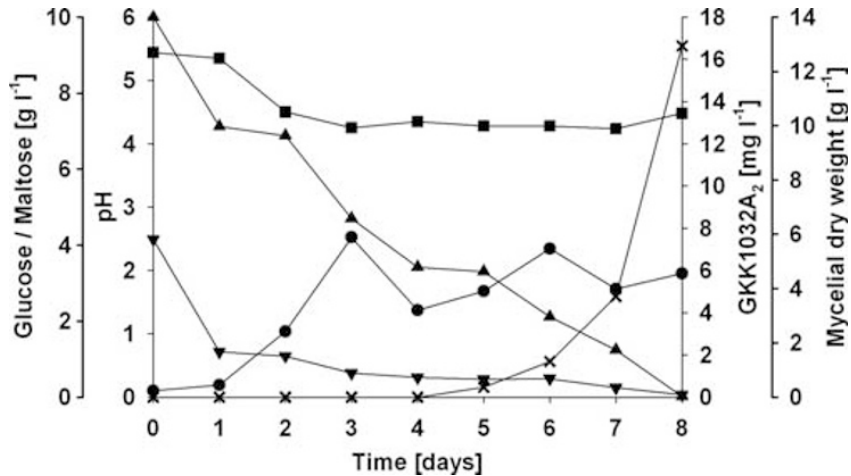

Figure 1 Fermentation diagram Penicillium sp. IBWF-029-96 in yeast malt glucose medium (20-I scale). •, mycelial dry weight; $\mathbf{\square}, \mathrm{pH} ; \boldsymbol{\Lambda}$, glucose; $\boldsymbol{\nabla}$, maltose; $\times$, GKK1032A $\mathrm{A}_{2}$.

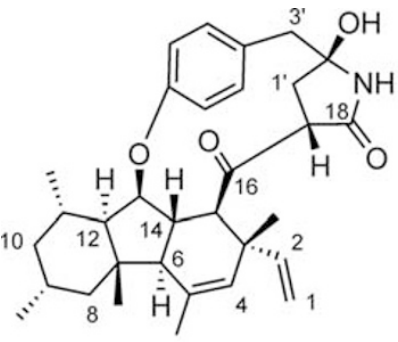

$1 \mathrm{GKK} 1032 \mathrm{~A}_{2}$

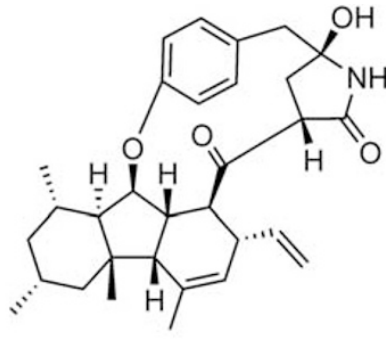

2 Pyrrocidine B
Figure 2 Structure of GKK1032A (1) and Pyrrocidine B (2).

shown in Figure 2, was analyzed by NMR and MS techniques. The obtained spectroscopic and physical data were in accordance to those given in earlier descriptions of the compound. ${ }^{6,7}$ The NMR data are shown in Table 1.

Resistance development and favorable ecotoxicological profiles of agrochemicals are the driving force for the development of novel plant protectants. Even though efficient fungicides for the treatment of rice blast are available, the disease caused by the fungus $M$. oryzae remains to be a serious problem. Therefore, the development of new fungicides with a new mode of action is required. Because of their enormous structural diversity, natural products are regarded to be excellent lead structures for the development of new agrochemicals. In addition, the fungal secondary metabolism represents a large source for bioactive structures. ${ }^{15}$ In this study, natural products from fungi were screened concerning their plant-protective activity towards M. oryzae. Compounds interfering with the infection-related morphogenesis in phytopathogenic fungi prevent the pathogen from entering and colonizing the host plant. In this context, pathogenic differentiation prior to plant penetration appears to hold targets for fungicides. The infection structures of $M$. oryzae are located on the host surface, and are therefore easily accessible. In addition, through the inhibition of the initial step in the infection process such as the conidial germination, the arising of resistances is minimized and it allows the application of specific and environmentally safe fungicides. ${ }^{4}$

In the screening for inhibitors of the infection-relevant structures in M. oryzae culture extracts of the fungus Penicillium sp. IBWF-029-96 caused an inhibition of conidial germination. The secondary metabo- 
Table $1{ }^{1} \mathrm{H}(400 \mathrm{MHz})$ and ${ }^{13} \mathrm{C}(101 \mathrm{MHz}) \mathrm{NMR}$ data of GKK1032A in $\mathrm{CDCl}_{3}$

\begin{tabular}{|c|c|c|}
\hline Position & $d_{H}$ & $d_{C}$ \\
\hline \multirow[t]{2}{*}{1} & $4.88(\mathrm{dd}, J=17.6,1.0 \mathrm{~Hz})$ & $112.2(\mathrm{t})$ \\
\hline & $4.82(\mathrm{dd}, J=10.6,1.0 \mathrm{~Hz})$ & \\
\hline 2 & $5.42(\mathrm{dd}, J=17.6,10.6 \mathrm{~Hz})$ & $146.3(d)$ \\
\hline 3 & - & $41.5(\mathrm{~s})$ \\
\hline 4 & 4.90 (br s) & $130.7(d)$ \\
\hline 5 & - & $138.6(\mathrm{~s})$ \\
\hline 6 & $1.87(\mathrm{~m})$ & $53.1(d)$ \\
\hline 7 & - & $41.5(\mathrm{~s})$ \\
\hline \multirow[t]{2}{*}{8} & $1.95(\mathrm{~m})$ & $49.0(\mathrm{t})$ \\
\hline & $0.79(\mathrm{t}, \mathrm{J}=12.1 \mathrm{~Hz})$ & \\
\hline 9 & $1.83(\mathrm{~m})$ & $28.1(\mathrm{~d})$ \\
\hline \multirow[t]{2}{*}{10} & $1.79(\mathrm{~m})$ & $45.6(t)$ \\
\hline & $0.61(\mathrm{q}, J=12.2 \mathrm{~Hz})$ & \\
\hline 11 & $1.90(\mathrm{~m})$ & $27.4(d)$ \\
\hline 12 & $1.06(\mathrm{dd}, J=11.2,7.7 \mathrm{~Hz})$ & $61.0(\mathrm{~d})$ \\
\hline 13 & $4.24(\mathrm{dd}, J=7.7,4.5 \mathrm{~Hz})$ & $90.8(d)$ \\
\hline 14 & 2.61 (ddd, $J=13.4,10.1,4.5 \mathrm{~Hz}$ ) & $50.7(d)$ \\
\hline 15 & $3.51(\mathrm{~d}, J=10.1 \mathrm{~Hz})$ & $56.7(d)$ \\
\hline 16 & - & $200.4(\mathrm{~s})$ \\
\hline 17 & $3.12(\mathrm{dd}, J=12.0,4.7 \mathrm{~Hz})$ & $56.8(d)$ \\
\hline 18 & - & $171.9(\mathrm{~s})$ \\
\hline \multirow[t]{2}{*}{$1^{\prime}$} & $2.89(\mathrm{~m})$ & $33.4(t)$ \\
\hline & $1.80(\mathrm{~m})$ & \\
\hline $2^{\prime}$ & - & $88.9(\mathrm{~s})$ \\
\hline $3^{\prime}$ & $2.92(\mathrm{~s})$ & $47.0(t)$ \\
\hline $4^{\prime}$ & - & $128.0(\mathrm{~s})$ \\
\hline $5 ’ a$ & $6.92(\mathrm{dd}, J=8.7,1.6 \mathrm{~Hz})$ & $133.5(d)$ \\
\hline $5{ }^{\prime} b$ & $7.14(\mathrm{dd}, J=8.1,1.6 \mathrm{~Hz})$ & $131.6(d)$ \\
\hline 6'a & $6.96(\mathrm{dd}, J=8.7,2.2 \mathrm{~Hz})$ & $118.9(\mathrm{~d})$ \\
\hline $6{ }^{\prime} b$ & $6.81(\mathrm{dd}, J=8.1,2.2 \mathrm{~Hz})$ & $124.5(d)$ \\
\hline $7^{\prime}$ & - & $159.9(\mathrm{~s})$ \\
\hline 3-Me & 1.19 (s) & $25.8(q)$ \\
\hline 5-Me & 1.86 (br s) & $21.0(q)$ \\
\hline 7-Me & $1.17(\mathrm{~s})$ & $16.1(q)$ \\
\hline 9-Me & $0.90(\mathrm{~d}, J=6.3 \mathrm{~Hz})$ & $22.9(q)$ \\
\hline 11-Me & $1.10(\mathrm{~d}, J=6.3 \mathrm{~Hz})$ & $19.9(q)$ \\
\hline $18-\mathrm{NH}$ & 5.99 (br s) & - \\
\hline
\end{tabular}

Carbon multiplicities were detected indirectly (HSQC). The numbering scheme from Oikawa ${ }^{7}$ was used.

lite GKK1032A $\mathrm{A}_{2}$ (1) was found responsible for this activity and was isolated from the mycelium. The polyketide is a known fungal secondary metabolite, which has been identified from cultures of the genus Penicillium before. ${ }^{6,7}$ The metabolite was isolated in this study, as it showed antimicrobial and antitumor activities against HeLa S3 cells. An antimicrobial activity against Staphylococcus and Enterococcus strains was also detected for pyrrocidine A and pyrrocidine B (2), 3,6-bisepi-3desmethyl analogs of 1 , whereas pyrrocidine A shows higher activities. ${ }^{16}$ An antifungal activity of these compounds was found as well, including Aspergillus and Fusarium strains. ${ }^{17}$ In our study, GKK1032A 2 (1) failed to inhibit vegetative growth of bacteria and fungi, whereas Jurkat cells were sensitive in presence of the compound. The second tested cell line, Colo-320, was not affected (Table 2). The reason for this low susceptibility might probably be due to missing receptors. ${ }^{18}$ Furthermore, no nematicidal activity was found.

GKK1032A 2 (1) seems to inhibit $M$. oryzae in a specific manner, as shown in Table 2 . The spore germination in the phytopathogenic fungi
Table 2 Cytotoxicity, inhibition of conidial germination and phytotoxicity of GKK1032 $A_{2}$ and pyrrocidine B

\begin{tabular}{|c|c|c|}
\hline \multirow[b]{2}{*}{ Organism } & GKK $1032 A_{2}$ & Pyrrocidine B \\
\hline & \multicolumn{2}{|c|}{$I_{50}\left[\mu g \mathrm{mI}^{-1}\right]$} \\
\hline \multicolumn{3}{|l|}{ Cell lines } \\
\hline Colo-320 & NE & $\mathrm{nt}$ \\
\hline HeLa S3 & $\mathrm{nt}$ & 25 \\
\hline Jurkat & 10 & nt \\
\hline \multicolumn{3}{|l|}{ Fungi } \\
\hline Botrytis cinerea & NE & NE \\
\hline Fusarium graminearum & NE & nt \\
\hline Magnaporthe oryzae & 3 & 2.5 \\
\hline Phytophthora infestans & $\mathrm{NE}$ & NE \\
\hline \multicolumn{3}{|l|}{ Plants } \\
\hline Lepidium sativum & $50-100$ & NE \\
\hline Oryza sativa & $\mathrm{NE}$ & nt \\
\hline Setaria italica & 100 & NE \\
\hline Triticum aestivum & $>100$ & nt \\
\hline
\end{tabular}

Abbreviations: NE, no effect; nt, not tested.

Table 3 Antimicrobial activity of GKK1032A $\mathrm{A}_{2}$ and pyrrocidine B in agar-diffusion assays

\begin{tabular}{lcc}
\hline & GKK1032A 2 & Pyrrocidine B \\
\cline { 2 - 3 } Organism & \multicolumn{2}{c}{${\mathrm{MIC}\left[\mu \mathrm{gm}^{-1}\right]}$} \\
\hline Bacteria & $\mathrm{NE}$ & $\mathrm{NE}$ \\
Bacillus brevis & $\mathrm{NE}$ & $\mathrm{nt}$ \\
B. subtilis & $\mathrm{NE}$ & $\mathrm{nt}$ \\
Micrococcus luteus & $\mathrm{NE}$ & $\mathrm{nt}$ \\
Enterobacter dissolvens & $\mathrm{NE}$ & $<10$ \\
Staphylococcus aureus & & \\
& & $\mathrm{NE}$ \\
Fungi & $\mathrm{NE}$ & $<10$ \\
Candida albicans & $\mathrm{NE}$ & $\mathrm{NE}$ \\
Magnaporthe oryzae & $\mathrm{NE}$ & $\mathrm{nt}$ \\
Mucor miehei & $\mathrm{NE}$ & $\mathrm{NE}$ \\
Nematospora coryli & $\mathrm{NE}$ &
\end{tabular}

Abbreviations: NE, no effect; nt, not tested.

F. graminearum, B. cinerea and $P$. infestans was not affected. In contrast, the vegetative growth of $M$. oryzae on CM plates was not inhibited (Table 3). However, the compound seems not to influence the respiration of the fungus. Pyrrocidine B (2), isolated from the unidentified fungal strain IBWF-012-06, inhibits $M$. oryzae in the same manner as $\mathbf{1}$, as shown in Table 2. Interestingly, 2 shows activity against the vegetative growth of M. oryzae as well (Table 3). Furthermore, we could confirm the activity of 2 against $S$. aureus, an effect not found for GKK1032 $\mathrm{A}_{2}$ (1). For pyrrocidine A, we cannot provide any further data.

Phytotoxic effects of $\mathbf{1}$ towards the host plant $O$. sativa were not observed. Sprout or root growth was not affected by the treatment. Furthermore, neither lesion formation nor necrosis was detected on leaves of O. sativa when exposed to the metabolite. In L. sativum and S. italic sprout growth was inhibited when exposed to $25 \mu \mathrm{g}$ of 1 . In 


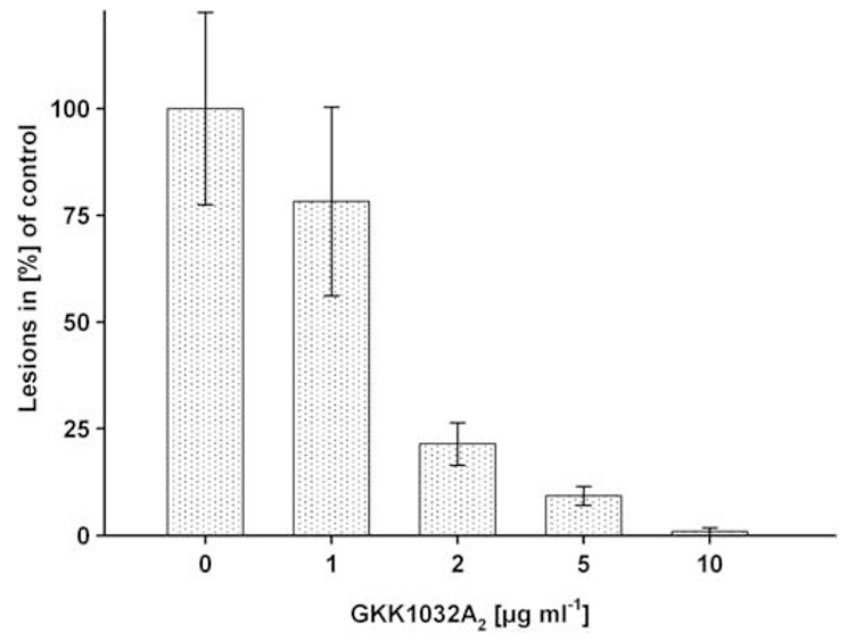

Figure 3 Protective effect of GKK1032A 2 on rice plants inoculated with a M. oryzae spore suspension.

contrast, decreased root growth was observed in T. aestivum upon exposure to $25 \mu \mathrm{g}$ of the compound. As T. aestivum and O. sativa are of economic importance, they appear to be the major application area for fungicides. Therefore, a low toxicity as found for $\mathbf{1}$ is desirable. The compound was found not to affect intact rice plants. Therefore, a protective treatment of rice plants appears to be possible. In our experiments, GKK1032 $\mathrm{A}_{2}$ (1) was found to show good plant-protective activity. At a concentration of $2 \mu \mathrm{g} \mathrm{ml}^{-1}$, lesion formation was reduced by $75 \%$. A complete protection was observed at a concentration of $10 \mu \mathrm{g} \mathrm{ml}^{-1}$ (Figure 3). Showing an $\mathrm{IC}_{50}$ of $3 \mu \mathrm{g} \mathrm{ml}^{-1}$, the germination assay emphasizes this result.

Refering to the chemical structures, the pyrrolidinone function of GKK1032 $\mathrm{A}_{2}(\mathbf{1})$ and the pyrrocidines has already been found in other antifungal compounds such as talaroconvolutin A. ${ }^{19}$ But the macrocycle containing ether, phenyl, pyrrolidinone and ketone functions seems to be very rare in natural compounds. However, there exist some studies about this tricarbocyclic systems. ${ }^{20,21} \mathrm{GKK} 1032 \mathrm{~A}_{2}$ (1) and the 3,6-bisepi-3-desmethyl analogs pyrrocidines A and B (2) show similar bioactivity. In the case of $\mathbf{1}$, there is a lack of antimicrobial activity. Furthermore, a different affect on the vegetative growth of $M$. oryzae could be shown for $\mathbf{1}$ and $\mathbf{2}$. Although the chemical structures are almost identical, there seems to be major differences in the biological activities.

Considering the costs of agrochemicals, the complex structure of the GKK1032 members does not appear to be a suitable lead for the development of a plant protectant. However, it could serve as a chemical lead for the identification of the molecular target and for toxophore studies. In this context, further experiments concerning the mode of action of the compound are required.

\section{CONFLICT OF INTEREST}

The authors declare no conflict of interest.

\section{ACKNOWLEDGEMENTS}

This work was financially supported by the state of Rheinland-Pfalz and the BASF SE. We are grateful to Dr John Speakman, BASF SE, for some of the fungal strains used as test organism in this study. We thank Anja Meffert for expert technical assistance. Helpful discussions with $\mathrm{H}$ Kolshorn (University of Mainz) are gratefully acknowledged.

1 Couch, B. C. \& Kohn, L. M. A multilocus gene genealogy concordant with host preference indicates segregation of a new species, Magnaporthe oryzae, from $M$ grisea. Mycologia 94, 683-693 (2002).

2 Talbot, N. J. On the trail of a cereal killer: exploring the biology of Magnaporthe grisea. Annu. Rev. Microbiol. 57, 177-202 (2003).

3 De Jong, J. C., McCormack, B. J., Smirnoff, N. \& Talbot, N. J. Glycerol generates turgor in rice blast. Nature 389, 471-483 (1997).

4 Thines, E., Anke, H. \& Weber, R. W. S. Fungal secondary metabolites as inhibitors of infection-related morphogenesis in phytopathogenic fungi. Mycol. Res. 108, 14-25 (2004).

5 Anke, T., Oberwinkler, F., Steglich, W. \& Schramm, G. The strobilurins - new antifungal antibiotics from the basidiomycete Strobilurus tenacellus. J. Antibiot. 30, 806-810 (1977).

6 Koizumi, F., Hasegawa, K., Ando, K., Ogawa, T. \& Hara, A. Antibiotic antitumor GKK1032 manufacture with Penicillium. Jpn. Kokat Tokkyo Koho Japanese Patent 2001247574 A2 (2001).

7 Oikawa, H. Biosynthesis of structurally unique fungal metabolite GKK1032A2: indication of novel carbocyclic formation mechanism in polyketide biosynthesis. J. Org. Chem. 68, 3552-3557 (2003).

8 Talbot, N. J., Ebbole, D. J. \& Hamer, J. E. Identification and characterization of MPG1, a gene involved in pathogenicity from the rice blast fungus Magnaporthe grisea. Plant Cell 5, 1575-1590 (1993).

9 Anke, H., Bergendorff, O. \& Sterner, O. Assay of the biological activities of guaiane sesquiterpenoids isolated from the fruit bodies of edible Lactarius species. Food Chem. Tox. 27, 393-398 (1989).

10 Stadler, M. et al. Lachnumon and lachnumol A, new metabolites with nematicidal and antimicrobial activities from the ascomycete Lachnum papyraceum (Karst.) Karst. J. Antibiot. 46, 961-967 (1993).

11 Mirabelli, C. K. et al. Application of a tissue culture microtiter test for the detection of cytotoxic agents from natural products. J. Antibiot. 38, 758-766 (1985).

12 Zapf, S., Hossfeld, M., Anke, H., Velten, R. \& Steglich, W. Darlucins A and B, new isocyanide antibiotics from Sphaerellopsis filum (Darluca filum). J. Antibiot. 48, 36-41 (1995).

13 Rieger, P. H., Liermann, J. C., Opatz, T., Anke, H. \& Thines, E. Caripyrin, a new inhibitor of infection-related morphogenesis in the rice blast fungus Magnaporthe oryzae. J. Antibiot. 63, 285-289 (2010).

14 Barnett, H. L. \& Hunter, B. B. I/lustrated Genera of Imperfect Fungi 4th edn, 90-91 (APS Press, St Paul, MN, 1998).

15 Shu, Y.- Z. Recent natural products based drug development: a pharmaceutical industry perspective. J. Nat. Prod. 61, 1053-1071 (1998).

$16 \mathrm{He}, \mathrm{H}$. et al. Pyrrocidines $\mathrm{A}$ and $\mathrm{B}$, new antibiotics produced by a filamentous fungus. Tetrahedron Lett. 43, 1633-1636 (2002).

17 Wicklow, D. T. \& Poling, S. M. Antimicrobial activity of pyrrocidines from Acremonium zeae against endophytes and pathogens of maize. Phytopathology 99, 109-115 (2009).

18 Gustafsson, J.-Á. Receptor-mediated toxicity. Toxicol. Lett. 82/83, 465-470 (1995).

19 Suzuki, S. et al. Antifungal substances against pathogenic fungi, talaroconvolutins, from Talaromyces convolutes. J. Nat. Prod. 63, 768-772 (2000).

20 Arai, N., Ui, H., Omura, S. \& Kuwajima, I. Studies toward the total synthesis of GKK1032A $\mathrm{A}_{2}$, a structurally unique antitumor compound: stereoselective construction of the tricarbocyclic system. Synlett 11, 1691-1694 (2005).

21 Shiono, Y. et al. Pyrrospirones A and B, apoptosis inducers in HL-60 cells, from an endophytic fungus, Neonectria ramulariae Wollenw KS-246. Bioorg. Med. Chem. Lett. 18, 6050-6053 (2008). 